\title{
Improved sealing ability promoted by calcium silicate-based root canal sealers
}

Tatiana Vieira de Melo, DDS, MSc'; Marina Carvalho Prado, DDS, MSc ${ }^{1,2}$; Raphael Hirata Jr, DDS, PhD; Sandra Rivera Fidel, DDS, $\mathrm{PhD}^{1}$; Emmanuel João Nogueira Leal da Silva, DDS, PhD ${ }^{1,2}$; Luciana Moura Sassone, DDS, $\mathrm{PhD}^{1}$

1 PROCLIN Department, School of Dentistry, State University of Rio de Janeiro (UERJ),

Rio de Janeiro, RJ, Brazil

${ }^{2}$ Department of Endodontics, School of Dentistry, Grande Rio University (UNIGRANRIO), Duque de Caxias, RJ, Brazil

${ }^{3}$ Deparment of Microbiology, School of Dentistry, State University of Rio de Janeiro (UERJ), Rio de Janeiro, RJ, Brazil

Aim: This study investigated the sealing ability produced by $\mathrm{AH}$ Plus (Dentsply DeTrey, Konstaz, Germany), EndoSequence BC sealer (Brasseler USA, Savannah, GA, USA), GuttaFlow (Coltène/ Whaledent, Altstätten, France) and MTA Fillapex (Angelus, Londrina, Brazil). Methdos: A total of forty-six single-root human canines were prepared and randomly divided into four experimental groups ( $n=10)$ : MTA Fillapex, EndoSequence BC Sealer, AH Plus or GuttaFlow. Teeth with intact crowns served as negative controls $(n=3)$ and teeth filled with only gutta-percha served as positive controls $(n=3)$. Teeth were mounted in a two-chamber apparatus and exposed to Enterococcus faecalis. The number of days over a 60-days period was recorded for the appearance of turbidity in the lower chamber. KaplanMeier method was used to estimate the survival curves. The nonparametric log-rank test was used to compare the survival curves using a significance level of 0.05. Results: The results at the end of the observation time were further analyzed by chi-square testing. All positive controls leaked within 24 h, whereas none of the negative controls leaked after 60 days. EndoSequence BC Sealer and MTA Fillapex had significant less bacterial leakage $(P<0.05)$ than the other tested sealers. No significant difference between $\mathrm{AH}$ Plus and GuttaFlow was observed $(P>0.05)$. Conclusion: In conclusion, calcium-silicate based root canal sealers promoted improved sealing ability when compared to other endodontic sealers.

Key words: Dental materials. Endodontics. Root canal sealers. 


\section{Introduction}

The aim of the root canal filling is to create a fluid-tight apical, lateral and coronal seal, thus perpetuating the state of disinfection obtained after chemomechanical preparation and intracanal medication'. This procedure minimizes the risks of infection or reinfection of the root canal system?'. The most widely accepted technique for root canal filling is the association of gutta-percha with an endodontic sealer. The main goals of the root canal sealer is to fill the interface between gutta-percha and the dentin walls, the voids inside gutta-percha, to fill root canal imperfections and increase adaption of the root filling, obtaining a hermetic seal'.

Over the last years, a new class of root canal sealers, named calcium-silicate-based sealers, has been commercially available. These sealers, such as MTA Fillapex (Angelus, Londrina, PR, Brazil) and EndoSequence BC Sealer (Brasseler USA, Savannah, GA, USA), can be regarded as an outgrowth of the mineral trioxide aggregate (MTA)'s clinical and scientific success. This means that the intention is to extrapolate the MTA's remarkable balance between biological and physical-chemical properties creating a close-to-ideal sealer, but showing proper flow rate to be used with gutta-percha cones and conventional and warm vertical filling techniques. Moreover, theoretically, handling, retreatability and bioactivity are present; thus, the so-called biomineralization process would be able to take place in the critical sealer-dentine interface ${ }^{2}$.

MTA Fillapex is a paste-paste sealer basically composed of MTA, salicylate resin, natural resin, bismuth and silica. According to the manufacturer, MTA Fillapex has adequate working time, high radiopacity and low solubility, providing sealing through expansion during setting. It was shown that MTA Fillapex has suitable physicochemical properties, however several studies demonstrate some concerns regarding its biological properties 3,4

EndoSequence BC Sealer is a premixed and injectable calcium silicate root canal sealer and, according to the manufacturer's description, it is composed of zirconium oxide, calcium silicates, calcium phosphate monobasic, calcium hydroxide and thickening agents ${ }^{5-7}$. It is a hydrophilic, insoluble, radiopaque and aluminum-free material based on calcium silicate composition, which utilizes the moisture naturally present in the dentinal tubules to initiate and complete its setting reaction. It has been demonstrated that EndoSequence has good bond strength ${ }^{5}$ and adequate physicochemical properties ${ }^{6,7}$.

Although some physicochemical properties of calcium silicate-based sealers have been extensively evaluated, there are only little inconsistent data about the sealing ability of this group of sealers using bacterial penetration methodology. Therefore, the present study was designed to investigate the sealing ability, a relevant aspect, produced by EndoSequence BC Sealer and MTA Fillapex. AH Plus (Dentisply DeTrey, Konstaz, Germany), a resin-based sealer, and GuttaFlow (Coltène/Whaledent, Altstätten, France), a silicon-based sealer, were also evaluated in the present study. The bacterial penetration assessment was used to test the hypothesis that the calcium silicate-based sealers (EndoSequence BC Sealer and MTA Fillapex) produced higher sealing ability than the AH Plus and GuttaFlow. 


\section{Material and Methods}

\section{Sample selection}

Forty-six human mandibular canines were selected and autoclaved. Then, each tooth were submitted to buccolingual and mesiodistal planes of periapical radiographs for analysis. The presence of lateral and accessory canals, caries, isthmus, cracks or fracture lines excluded specimens from this study. Following this, the total sample were stored in $10 \%$ neutral formalin.

\section{Chemomechanical preparation}

From the total sample, three teeth with intact crowns did not receive any preparation, serving as a negative control group. Therefore, only forty-three teeth were prepared by the same operator, using the same technique. Access cavity was conventionally made using diamond burs and EndoZ (Dentsply Maillefer, Ballaigues, Switzerland). Before and after the completion of preparation procedures, the patency of each canal was checked by exceeding a size \#15 K-file through the apical foramen. After that, the working length was stablish up to $1 \mathrm{~mm}$ short of the foramen and root canals were instrumented using a full sequence of ProTaper Universal files (Dentsply Maillefer, Ballaigues, Switzerland) as follows: (1) S1 file, (2) SX file, (3) S2 file, (4) F1, (5) F2, (6) F3, (7) F4 and (8) F5 files. During each change of files, canals were irrigated with $2 \mathrm{~mL}$ of freshly prepared $5.25 \% \mathrm{NaOCl}$. Following preparation, root canals received a final flush of $2 \mathrm{~mL}$ of $17 \%$ EDTA for 3 min and were dried with F5 paper points (Dentsply Maillefer). Thereafter, prepared teeth were randomly divided into one positive control group $(n=3)$ and four experimental groups $(n=10)$.

\section{Root Canal Filling}

All forty-three prepared teeth were root filled by the same operator using the cold lateral compaction technique. The three specimens selected for the positive control group were filled with gutta-percha and no root canal sealer. The forty teeth from the 4 experimental groups were filled with gutta-percha and one of the following root canal sealers: MTA Fillapex, EndoSequence BC Sealer, AH Plus or GuttaFlow. The sealers were prepared following the manufactures instructions. A F5 master gutta-percha cone was placed into the canals to the full working length. Lateral compaction technique was undertaken by inserting ten accessory gutta-percha cones (MF, Odous De-Deus, Belo Horizonte, MG, Brazil) with the use of a size B endodontic finger spreader (Dentsply Maillefer). The excess of coronal gutta-percha was removed by a heated instrument.

Except from the apical and coronal extremities, two coats of nail varnish were applied on the external surface of all specimens. Then, filled teeth were stored at $37^{\circ} \mathrm{C}$ and $100 \%$ humidity for 14 days.

\section{Bacterial penetration model}

Afterwards, the bacterial penetration test was performed in a two chamber set-up as previously described ${ }^{8}$. Ten $\mathrm{mL}$ glass assay tubes (BD Vacutainer, Juiz de Fora, MG, Brazil) with rubber stops were adjusted for application. Then, a hole was prepared in the 
central point of each rubber stopper using heated instrument, in order to insert a cylinder that was prepared from insulin syringes. Specimens tooth crown was tightly adjusted into the rubber tube and sealed by cyanoacrylate (Loctite 496, Henkel Ltda, São Paulo, $\mathrm{SP}, \mathrm{Brazil)}$. Then, on the opposite side of this rubber tube, syringe cylinders were fitted to produce a reservoir for the medium and cyanoacrylate was inserted in all junctions of this structure. The apparatus external surface was sealed with cyanoacrylate and Parafilm M (Laboratory Film, American National Can, Chicago Illinois, USA) (Figure 1).

After that, the apparatus was overnight sterilized with ethylene oxide gas (BIOXXI Esterilization Services Ltda, Rio de Janeiro, RJ, Brazil). The setup was accomplished in a laminar airflow hood, in which $3 \mathrm{~mL}$ sterile Brain Heart Infusion (BHI, Oxoid Ltda, Basingstoke, UK) was inserted in the glass assay tubes in such a way as to immerse approximately $2 \mathrm{~mm}$ of the resected root in the broth. To assure sterilization of this bacterial penetration model, the entire system was incubated during 4 days at $37^{\circ} \mathrm{C}$. The upper chamber was filled with medium without bacteria on day 1 and checked for penetration until day 0. Enterococcus faecalis (ATCC-29212) was added to the upper chamber and the time for $E$. faecalis to eventually penetrate into the lower chamber was noted. The apparatus was incubated at $37^{\circ} \mathrm{C}$ and daily checked. Bacteria penetrating along the root filling were detected by turbidity observed in the lower chamber. Maximum observation time was 60 days.

\section{Statistical Analysis}

The Kaplan-Meier method was used to estimate the survival curves. Specimens that did not leak until the end of the observation time were computed with an event time

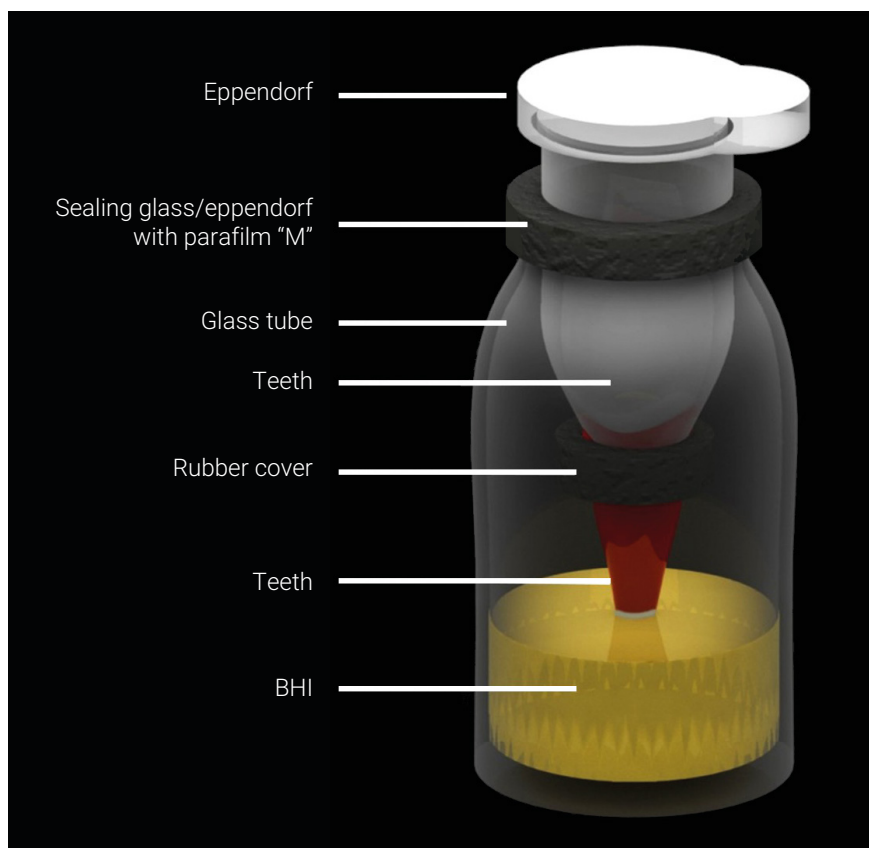

Figure 1. Setup of the model design. 
of 60 days as censored variables. The nonparametric log-rank test was used to compare the survival curves using a significance level of 0.05 . The results at the end of the observation time (60 days) were further analyzed by chi-square testing.

\section{Results}

All specimens of the positive control group leaked within $24 \mathrm{~h}$, whereas no bacterial penetration was observed in the negative control group after the observation time of 60 days. Overall, $60 \%$ of the samples of AH Plus and $40 \%$ of GuttaFlow group were fully contaminated after 60 days, whereas $10 \%$ and $20 \%$ of the EndoSequence BC Sealer and MTA Fillapex groups were fully contaminated, respectively. EndoSequence BC Sealer and MTA Fillapex demonstrated significant lower specimens to become contaminated in comparison with AH Plus and GuttaFlow $(P<0.05)$ (Figure 2). No significant difference between AH Plus and GuttaFlow was observed $(P>0.05)$.

\section{Discussion}

According to the current results, bacterial penetration occurred in all tested groups regardless of the endodontic sealer used, thus, we currently cannot achieve the ideal outcome with the existent materials. However, the use of calcium silicate-based root canal sealers resulted in significantly fewer samples being contaminated at the end of the experimental period when compared to the other tested sealers $(P<0.05)$. Therefore, the tested hypothesis was sustained. Previous studies demonstrated good sealing ability of calcium-silicate based root repair materials ${ }^{9,10}$ and indicated the clinical use of MTA-based sealers as apical barrier in wide-open apices as it may stop/reduce the fluid flow rate through the apex ${ }^{11}$. Moreover, other studies demonstrated suitable sealing ability of calcium-silicate based sealers using fluid-filtration method ${ }^{12,13}$; however, there are only little inconsistent data about the sealing ability of this group of sealers using bacterial penetration methodology. Endosequence BC Sealer presented a superior sealing ability than AH Plus in a dye penetration evaluation ${ }^{14}$, consisting with

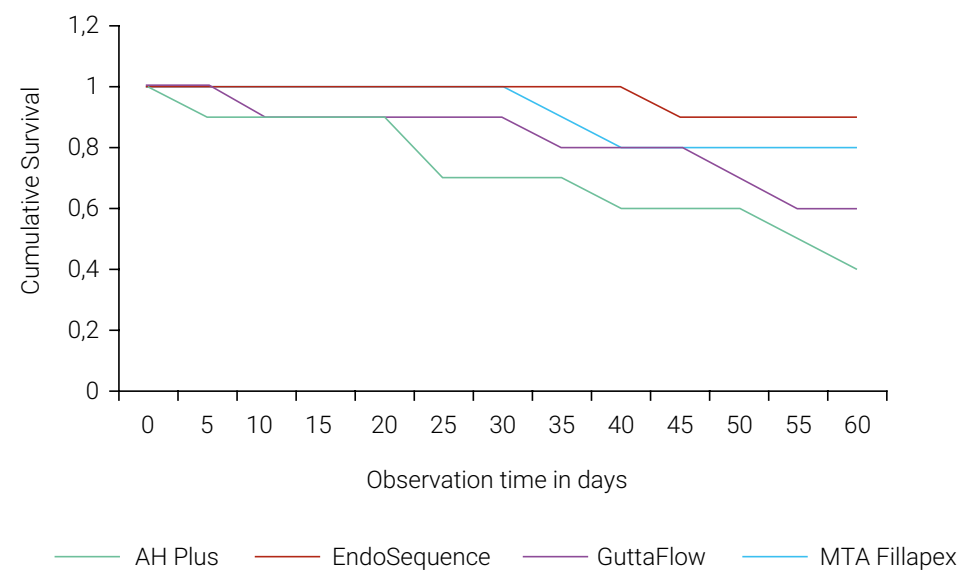

Figure 2. Kaplan-Meier survival curves for the experimental root canal sealers in the bacterial leakage test. 
the present results. In contrast, MTA Fillapex has demonstrated controversial sealing performance in endodontic literature ${ }^{13,15-18}$, what may result from its physicochemical properties ${ }^{19}$ and differences in experimental designs such as the evaluation technique.

The results obtained by calcium silicate-based sealers compared to the other sealers may be caused, in part, by its extremely small particle size and excellent level of viscosity, which enhances flow of the sealer into dentinal tubules, anatomic irregularities, and gutta-percha ${ }^{3,7}$. Additionally, EndoSequence BC Sealer and MTA Fillapex exhibits minimal or no shrinkage during the setting phase ${ }^{6}$, which may have contributed to the higher sealing ability values. Moreover, the performance of calcium silicate-based sealers may be attributable to its bioactivity ${ }^{20}$, that is, the capacity to produce spontaneously an apatite layer when in contact with phosphate-containing physiological fluids. During set, the calcium silicate that is present in these sealers generates calcium hydroxide and calcium silicate hydrogel. Following this, part of the produced calcium hydroxide reacts with phosphate, providing hydroxyapatite and water. This spontaneous precipitation may promote a biomineralization process creating a chemical adhesion, improving sealing ability of the sealer ${ }^{21}$.

Epoxy resin-based AH Plus is well known for its long-term dimensional stability, expansive properties and ability to bond to dry dentine ${ }^{9,10,12}$. Moreover, AH Plus is thought to be able to react with any exposed amino groups in collagen to form covalent bonds between the resin and collagen. Despite these good properties, in the present study AH Plus allowed more samples to become contaminated over the experimental period, in agreement with several previously published studies, 82,23 . Sealing ability is related to different phenomenon such as porosity, marginal adaptation and hydrophilicity, explaining why AH Plus did not have the best sealing ability amongst the tested materials ${ }^{24,25}$. Another possible explanation is the inadequate bonding between AH Plus sealer and gutta-percha, allowing bacteria penetration at this interface.

Many laboratory studies comparing the sealing ability of GuttaFlow has also been published ${ }^{8,22,23}$. However, there is a lack of consensus in regard to the results obtained by this sealer. The discrepancies among studies could be explained on the basis of differences in experimental designs (eg. obturation technique and/or methodological differences). In the present study, using the same experimental design, GuttaFlow showed inferior sealing ability when compared to EndoSequence BC Sealer and MTA Fillapex $(P<0.05)$. It is important to emphasize that this is one of the first's studies to compare the sealing ability promoted by calcium silicate-based endodontic sealers in comparison to silicone-based endodontic sealers.

In the past, leakage was assessed using dye penetration methodologies. However, the reliability, reproducibility, and clinical relevance of these methods are questionable ${ }^{26,27}$. Moreover such dyes have low molecular weights and can penetrate into sites where protein and pathogens cannot penetrate ${ }^{28}$. Studies using bacterial cultures have been used widely to test the penetration resistance of endodontic sealers as it might be more meaningful and provides more precise and reproducible data ${ }^{29,30}$. Such tests may be considered to have more biological significance than dye leakage tests as they reflect more closely the clinical situation, and also allows the evaluation of the samples at specific periods ${ }^{29,30}$. However, it still uses a static model, thus it requires long periods of observation and it does not allow the quantification of the penetrat- 
ing bacteria ${ }^{29}$. E. faecalis was chosen as the test bacteria, as they are part of normal microbiota in humans and are frequently isolated in secondary infections. Using human saliva is advantageous to some degree because it closely approximates to the real clinical situation; on the other hand, it does not simulate temperature changes, the influence of diet, and salivary flow ${ }^{29}$.

In conclusion, calcium-silicate based root canal sealers promoted improved sealing ability when compared to other endodontic sealers.

\section{Acknowledgment:}

The authors would like to thank FAPERJ (Proc. E-26/202.839/2015) for scholarship support.

\section{References}

1. Peters LB, Wesselink PR, Moorer WR. The fate and role of bacteria left in root dentinal tubules. Int Endod J. 1995 Mar;28(2):95-9.

2. Gandolfi MG, Taddei P, Tinti A, De Stefano Dorigo E, Rossi PL, Prati C. Kinetics of apatite formation on a calcium-silicate cement for root-end filling during ageing in physiological-like phosphate solutions. Clin Oral Investig. 2010 Dec;14(6):659-68. doi: 10.1007/s00784-009-0356-3.

3. Silva EJ, Rosa TP, Herrera DR, Jacinto RC, Gomes BP, Zaia AA. Evaluation of cytotoxicity and physicochemical properties of calcium silicate-based endodontic sealer MTA Fillapex. J Endod. 2013 Feb;39(2):274-7. doi: 10.1016/j.joen.2012.06.030.

4. Silva EJ, Santos CC, Zaia AA. Long-term cytotoxic effects of contemporary root canal sealers. J Appl Oral Sci. 2013 Jan-Feb;21(1):43-7

5. Shokouhinejad N, Gorjestani H, Nasseh AA, Hoseini A, Mohammadi M, Shamshiri AR. Push-out bond strength of gutta-percha with a new bioceramic sealer in the presence or absence of smear layer. Aust Endod J. 2013 Dec;39(3):102-6. doi: 10.1111/j.1747-4477.2011.00310.x.

6. Zhou HM, Shen Y, Zheng W, Li L, Zheng YF, Haapasalo M. Physical properties of 5 root canal sealers. J Endod. 2013 Oct;39(10):1281-6. doi: 10.1016/j.joen.2013.06.012

7. Candeiro GT, Correia FC, Duarte MA, Ribeiro-Siqueira DC, Gavini G. Evaluation of radiopacitiy, pH, release of calcium ions, and flow of a bioceramic root canal sealer. J Endod. 2012 Jun;38(6):842-5. doi: 10.1016/j.joen.2012.02.029

8. De-Deus G, Brandão MC, Fidel RA, Fidel SR. The sealing ability of GuttaFlow in oval-shaped canals: an ex vivo study using a polymicrobial leakage model. Int Endod J. 2007 Oct;40(10):794-9.

9. Jeevani E, Jayaprakash T, Bolla N, Vemuri S, Sunil CR, Kalluru RS. Evaluation of sealing ability of MM-MTA, Endosequence, and biodentine as furcation repair materials: UV spectrophotometric analysis. J Conserv Dent. 2014 Jul;17(4):340-3. doi: 10.4103/0972-0707.136449.

10. Nair U, Ghattas S, Saber M, Natera M, Walker C, Pileggi R. A comparative evaluation of the sealing ability of 2 root-end filling materials: an in vitro leakage study using Enterococcus faecalis. Oral Surg Oral Med Oral Pathol Oral Radiol Endod. 2011 Aug;112(2):e74-7. doi: 10.1016/j.tripleo.2011.01.030.

11. Prati C, Siboni F, Polimeni A, Bossu M, Gandolfi MG. Use of calcium-containing endodontic sealers as apical barrier in fluid-contaminated wide-open apices. J Appl Biomater Funct Mater. 2014 Dec 30;12(3):263-70.DOI: 10.5301/jabfm.5000162.

12. Ersahan S, Aydin C. Solubility and apical sealing characteristics of new calcium silicate-based root canal sealer in comparison to calcium hydroxide-, methacrylate resin- and epoxy resin-based sealers. Acta Odontol Scand. 2013 May-Jul;71(3-4):857-62. doi: 10.3109/00016357.2012.734410. 
13. Asawaworarit W, Yachor P, Kijsamanmith K, Vongsavan N. Comparison of the the apical sealing ability of calcium silicate-based sealer and resin-based sealer using the fluid-filtration technique. Med Princ Prac. 2016;25(6):561-5.

14. Pawar SS, Pujar MA, Makandar SD. Evaluation of the apical sealing ability of bioceramic sealer, AH plus \& epiphany: An in vitro study. J Conserv Dent. 2014 Nov;17(6):579-82. doi: 10.4103/0972-0707.144609.

15. Jafari F, Sobhani E, Samadi-Kafil H, Pirzadeh A, Jafari S. In vitro evaluation of the sealing ability of three newly developed root canal sealers: A bacterial microleakage study. J Clin Exp Dent. 2016 Dec;8(5):e561-5.

16. Razavian H, Barekatain B, Shadmehr E, Khatami M, Bagheri F, Heidari F. Bacterial leakage in root canals filled with resin-based and mineral trioxide aggregate-based sealers. Dent Res J (Isfahan). 2014 Sep;11(5):599-603.

17. Ahuja $L$, Jasuja P, Verma KG, Juneja $S$, Mathur A, Walia R, et al. A comparative evaluation of sealing ability of new MTA based sealers with conventional resin based sealer: An in-vitro study. J Clin Diagn Res. 2016 Jul;10(7):ZC76-9. doi: 10.7860/JCDR/2016/18909.8194.

18. Singh R, Pushpa S, Arunagiri D, Sawhny A, Misra A, Sujatha R. The effect of irrigating solutions on the apical sealing ability of MTA Fillapex and Adseal root canal sealers. J Dent Res Dent Clin Dent Prospects. 2016 Fall;10(4):251-256. doi: 10.15171/joddd.2016.040

19. Vitti RP, Prati C, Sinhoreti MA, Zanchi CH, Souza E Silva MG, Ogliari FA, et al. Chemical-physical properties of experimental root canal sealers based on butyl ethylene glycol disalicylate and MTA. Dent Mater. 2013 Dec;29(12):1287-94. doi: 10.1016/j.dental.2013.10.002

20. Han L, Okiji T. Bioactivity evaluation of three calcium silicate-based endodontic materials. Int Endoc J. 2013 Sep;46(9):808-14. doi: 10.1111/iej.12062.

21. Reyes-Carmona JF, Felippe MS, Felippe WT. Biomineralization ability and interaction of mineral trioxide aggregate and white portland cement with dentin in a phosphate-containing fluid. J Endod. 2009 May;35(5):731-6. doi: 10.1016/j.joen.2009.02.011.

22. Bouillaguet S, Shaw L, Barthelemy J, Krejci I, Wataha JC. Long-term sealing ability of Pulp Canal Sealer, AH-Plus, GuttaFlow and Epiphany. Int Endod J. 2008 Mar;41(3):219-26.

23. Brackett MG, Martin R, Sword J, Oxford C, Rueggeberg FA, Tay FR, et al. Comparison of sea after obturation techniques using a polydimethylsiloxane-based root canal sealer. J Endod. 2006 Dec;32(12):1188-90

24. Resende LM, Rached-Junior FJA, Versiani MA, Souza-Gabriel AE, Miranda CE, Silva-Sousa YT, et al. A comparative study of physicochemical properties of AH Plus, Epiphany and Epiphany SE root canal seralers. Int Endod J. 2009 Sep;42(9):785-93. doi: 10.1111/j.1365-2591.2009.01584.x.

25. Schwartz RS. Adhesive dentistry and endodontics. Part 2: bonding in the root canal system-the promise and the problems: a review. J Endod. 2006 Dec;32(12):1125-34.

26. De Bruyne MA, Verhelst PC, De Moor RJ. Critical analysis of leakage studies in endodontics. Rev Belge Med Dent. 2005;60(2):92-106

27. Wu ML, Van B, Wesselink PR. Diminished leakage along root canals filled with gutta-percha without sealer over time: a laboratory study. Int Endod J. 2000 Mar;33(2):121-5.

28. Barthel CR, Moshonov J, Shuping G, Orstavik D. Bacterial leakage versus dye leakage in obturated root canals. Int Endod J. 1999 Sep;32(5):370-5.

29. Siqueira JF Jr, Rôças IN, Favieri A, Abad EC, Castro AJ, Gahyva SM. Bacterial leakage in coronally unsealed root canals obturated with 3 different techniques. Oral Surg Oral Med Oral Pathol Oral Radiol Endod. 2000 Nov;90(5):647-50

30. Siqueira JF Jr, Rôças IN, Lopes HP, de Uzeda M. Coronal leakage of two root canal sealers containing calcium hydroxide after exposure to human saliva. J Endod. 1999 jan;25(1):14-6 